\title{
Idiopathic Scoliosis
}

\section{GAS EXCHANGE AND THE AGE DEPENDENCE OF ARTERIAL BLOOD GASES}

\author{
ENID R. KAFER \\ From the Departments of Anesthesiology and Physiology, University of North \\ Carolina, Chapel Hill, North Carolina 27514, and Department of Medicine, \\ University of Sydney, Sydney 2006, New South Wales, Australia
}

A B S T R A C T The aims were to examine the gas exchange and arterial blood gas abnormalities among patients with scoliosis, and the correlation of these abnormalities with age and severity of deformity.

Means among 51 patients were as follows: age $25.4 \pm$ $17.5 \mathrm{yr}$, angle of scoliosis $80.2 \pm 29.9$ (SD), vital capacity $1.94 \pm 0.91$ (SD) (i.e. $60.6 \pm 19.2 \%$ of predicted), $\mathrm{PaO}_{2}$ $85.8 \pm 12.0$ (SD), $\mathrm{PaCo}_{3} 42.4 \pm 8.0$, physiological dead space to tidal volume ratio $0.438 \pm 0.074$ (SD), and alveolar-arterial oxygen difference breathing air $14.9 \pm$ 8.9 (SD).

Statistically significant correlations were as follows: the $\mathrm{PacO}_{2}$ and physiological dead space to tidal volume ratio increased with age, and the $\mathrm{PaO}_{2}$ and alveolar ventilation decreased with age. The $\mathrm{PaO}_{2}$, alveolar ventilation, and tidal volume were inversely related to the angle of scoliosis and directly related to the vital capacity, percent predicted vital capacity, and the compliance of the respiratory system. The physiological dead space to tidal volume ratio and the alveolar-arterial oxygen difference were inversely related to the vital capacity, percent predicted vital capacity, and the compliance of the respiratory system. $\mathrm{PaCO}_{2}$ was directly related to the elastance of the respiratory system.

We conclude that ventilation-blood flow maldistribution as a result of deformity of the rib cage was the primary abnormality in gas exchange, and that with age there was progressive deterioration in gas exchange. The age-dependent increase in $\mathrm{PaCO}_{2}$ and decrease in alveolar ventilation were due to the increasing physiological dead space to tidal volume ratio and failure of a compensatory increase in ventilation.

Received for publication 30 January 1976 and in revised form 14 June 1976.

\section{INTRODUCTION}

Respiratory function abnormalities are common in idiopathic scoliosis and may lead to respiratory failure (15 ). Blood gas abnormalities in scoliosis have been attributed to alveolar hypoventilation as a result of a ventilatory pattern of small tidal volumes $\left(\mathrm{V}_{\mathbf{T}}\right)^{1}$ and a high respiratory frequency (3-5). However, the most common blood gas abnormality is a reduced arterial oxygen tension $\left(\mathrm{PaO}_{2}\right)$ with a normal arterial carbon dioxide tension $\left(\mathrm{Paco}_{2}\right)(1-10)$. The reduced $\mathrm{PaO}_{2}$ and elevated alveolar-arterial oxygen differences $\left(\mathrm{AaDo}_{2}\right)$, and dead space $\left(V_{n}\right)$-tidal volume ratios $\left(V_{\mathrm{D}} / \mathrm{V}_{\mathrm{T}}\right)$ are indicative of ventilation/blood flow maldistribution (1-3, 6-10). Interpretation of previous data on gas exchange and arterial blood gases in scoliosis is difficult because some of the studies have included patients with scoliosis due to different etiologies or coexistent chronic pulmonary disease, some have too few patients for statistical analyses, and in some the severity of scoliosis has not been documented.

The objectives of the present investigation were to measure the steady-state gas exchange and arterial blood gases in large number of patients with idiopathic scoliosis, ranging widely in age and severity of scoliosis, and free of coexistent pulmonary disease; to utilize statistical techniques in the examination of the factors associated with blood gas and gas exchange abnormalities; and to examine the relative contribution of ventilation-blood

\footnotetext{
${ }^{1}$ Abbreviation used in this paper: $\mathrm{AaDo}_{2}$, alveolar-arterial oxygen differences; Crs, compliance of the respiratory system; $\mathrm{PaCO}_{2}$, arterial carbon dioxide tension; $\mathrm{PaO}_{2}$, arterial oxygen tension; $\dot{\mathrm{V}}_{\Delta} / \dot{Q}$, ventilation/perfusion ratio; $\mathrm{VC}$, vital capacity; $\mathrm{V}_{\mathrm{D}}$, dead space; $\mathrm{V}_{\text {Danat }}$, anatomical dead space; $V_{T}$, tidal volume.
} 
flow maldistribution and hypoventilation in the genesis and progression of blood gas abnormalities. This study was combined with an examination of lung volumes, mechanical properties of the respiratory system, ventilatory response to $\mathrm{CO}_{2}$ (which demonstrated associations between angle of scoliosis and lung volumes), and the elastic properties of the respiratory system, and between these variables and the slope and pattern of the ventilatory response to $\mathrm{CO}_{2}$. There was also evidence of an agedependent decrease in the slope of the ventilatory response to $\mathrm{CO}_{2}$ (11).

To circumvent the inadequacy of the angle of scoliosis as an esimate of the deformity of the rib cage, for which there is no quantitative estimate, the data on the lung volumes and the elastic properties of the respiratory system were used as indices of the severity of the deformity. In the analyses of the data, attention was directed to the association of gas exchange and blood gas abnormalities with age, angle of scoliosis, lung volumes, and the elastic properties of the respiratory system.

\section{METHODS}

Patients. Studies were performed on 51 patients with idiopathic scoliosis (14 male, 37 female) (Table I). The methods and results of measurement of lung volumes, mechanical properties of the respiratory system, and the ventilatory response to $\mathrm{CO}_{2}$ have been reported in an earlier paper (11), as has the method of measurement of the angle of scoliosis. The patients were in their usual state of health, and they were asymptomatic except for dyspnea in some patients. Patients with coexistent obstructive pulmonary disease were excluded from the series. No patient had received any corrective procedure for scoliosis, and they were life-long residents of Sydney or rural New South Wales. All were nonsmokers. The electrocardiograms were normal in all except two patients and the abnormalities were, respectively, right ventricular hypertrophy (patient 50 ) and poor progression of the $R$ wave in the precordial leads (patient 51).

Steady-state gas exchange studies. Studies were performed with the patients sitting. The patient breathed air from a Tissot gasometer via a one-way respiratory valve; expired gas was collected for two periods of $2-3 \mathrm{~min}$, and arterial blood was withdrawn during each collection. The apparatus dead space of the valve and mouthpiece was 30 ml. The patient then breathed $100 \%$ oxygen from the gasometer for $12 \mathrm{~min}$, and during the last $2 \mathrm{~min}$ the expired gas and arterial blood were collected. The data from the second of the two periods breathing air and from the oxygen-breathing period are reported. The expired gas was analyzed for carbon dioxide and oxygen concentration with a respiratory mass spectrometer (MS4 Associated Electrical Industries Ltd., London, U. K.) ; or $\mathrm{CO}_{2}$ was measured by an infrared $\mathrm{CO}_{2}$ analyzer (Godart Capnograph, De Bilt, Holland), and oxygen concentration was measured by a paramagnetic oxygen analyzer (Servomex oxygen analyzer DCL 101 Mark II, Crowborough, U. K.).

The carbon dioxide tension in the arterial blood was measured with a carbon dioxide electrode (Instrumentation Laboratory, Inc., Lexington, Mass.) and oxygen tension with a polarographic electrode. Both electrodes were cali- brated with three standard gas mixtures saturated with water vapor at $37^{\circ} \mathrm{C}$, and $\mathrm{PaO}_{2}$ was corrected for the difference between gas and tonometered blood (blood gas factor). The coefficients of variation of measurement of $\mathrm{PaCO}_{2}$ and $\mathrm{PaO}_{2}$ were $1.4 \%$ and $1.0 \%$, respectively. The $\mathrm{pH}$ was measured with an Electronics Instrumentation Laboratory microcapillary electrode (London, U. K.) and an EIL Vibron $\mathrm{pH}$ meter. Conventional methods were used for the calculation of $\mathrm{V}_{\mathrm{D}} / \mathrm{V}_{\mathrm{T}}$, and $\mathrm{AaDo}_{2}$ during air-breathing, and oxygen-breathing.

Analyses of data. To evaluate the effects of scoliosis independently of development during childhood and adolescence, the data for patients $\mathbf{1 8} \mathrm{yr}$ or older were examined, and to examine the effects of severe scoliosis, the data on patients with an angle of $80^{\circ}$ or more were also examined.

\section{RESULTS}

Physical characteristics. The age, angle of scoliosis, and body weight are in Table I. The mean vital capacity (VC), was 1.94 liters \pm 0.91 (SD), the mean percent predicted vital capacity was $60.6 \pm 19.2(\mathrm{SD})$, and the mean compliance of the respiratory system $\left(\mathrm{C}_{\mathrm{rs}}\right)$ was $48 \mathrm{ml} / \mathrm{cm} \mathrm{H} \mathrm{H}_{2} \mathrm{O} \pm 25$ (SD). Significant correlations were found between the angle and the VC $(r=-0.485, P<$ $0.001)$, percent predicted VC $(r=-0.523, P<0.001)$, and $\mathrm{Crs}(r=-0.625, P<0.001)$.

Gas exchange and arterial blood gases. The mean values for gas exchange and arterial blood gases for the total and for the subgroups are similar. In the total group (Fig. 1a) and both subgroups of patients, the Paoa was inversely related to the age. In that subgroup where the angle was $80^{\circ}$ or more, the correlation coefficient was $-0.507(P=0.001-0.01)$ and in that subgroup where the age was $18 \mathrm{yr}$ or older, the correlation coefficient was $-0.715(P<0.001)$. All three intercepts were below $100 \mathrm{~mm} \mathrm{Hg}$, and the rate of decline was $3.1-4.5 \mathrm{~mm} \mathrm{Hg} /$ decade. In the total group, the $\mathrm{Pao}$ was also inversely related to the angle (Fig. $1 \mathrm{~b})$, and directly related to the VC $(r=0.562, P<$ $0.001)$, the percent predicted VC $(r=0.539, P<0.001)$, and the $\mathrm{C}_{\mathrm{rs}}(r=0.450, P=0.001)$. The correlation coefficients for both subgroups were similar to those for the total group.

The $\mathrm{PaCO}$ was directly related to the age; for the total group the increase per decade was $3.23 \mathrm{~mm} \mathrm{Hg}$ (Fig. $2 a$ ). There were also statistically significant correlation coefficients between the $\mathrm{PaCO}_{2}$ and the elastance of the respiratory system for the total group (Fig. $2 b$ ) and for both subgroups, i.e. for those with an angle of $80^{\circ}$ or more, $r=0.497(P=0.001-0.01)$, and for those $18 \mathrm{yr}$ or older, $r=0.562(P=0.01)$. The $\mathrm{PaCO}_{2}$ was also inversely related to the VC $(r=-0.467, P=0.01-$ $0.05)$, percent predicted VC $(r=-0.507, P=0.001-$ $0.01)$ and to the $\operatorname{Crs}(r=-0.426, P=0.01-0.05)$ for the patients $18 \mathrm{yr}$ or older.

The incidence of elevated $V_{D} / V_{T}$ ratios and AaDos were high, and to estimate the incidence and severity of 
TABLE I

Gas Exchange, Arterial Blood Gases, $V_{D} / V_{T}$ Ratios, and Alveolar-Arterial Oxygen Difference while Breathing Air, and Alveolar-Arterial Oxygen Difference while Breathing 100\% Oxygen

\begin{tabular}{|c|c|c|c|c|c|c|c|c|c|c|c|c|c|}
\hline $\begin{array}{l}\text { Patient } \\
\text { number }\end{array}$ & Age & $\begin{array}{l}\text { Angle of } \\
\text { scoliosis }\end{array}$ & Weight & $\dot{\mathbf{V}}_{\mathbf{E}}$ & $\mathbf{V}_{\mathbf{T}}$ & $\dot{\mathrm{V}} \mathrm{O}_{2}$ & $\mathbf{R Q}$ & PaOz & $\mathrm{PaCO}_{2}$ & $\begin{array}{l}\mathbf{V D}_{\mathbf{D}} / \mathbf{V}_{\mathbf{T}} \\
\text { ratio }\end{array}$ & $\mathrm{AaDo}_{2}$ & $\dot{\mathbf{V}}_{\mathbf{A}}$ & $\begin{array}{c}\text { AaDoz } \\
100 \% \\
\text { oxygen }\end{array}$ \\
\hline & $y r$ & - & kg & $\begin{array}{c}\text { liter } / \min \\
\text { BTPS }\end{array}$ & $m l B T P S$ & 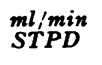 & & $m m H_{g}$ & $m m \boldsymbol{H g}$ & & $m m H_{g}$ & $\underset{B T P S}{\operatorname{liter} / \min }$ & \\
\hline 1 & 9 & 120 & 18 & 4.40 & 281 & 141 & 0.91 & 94 & 37 & 0.317 & 15 & 3.01 & 70 \\
\hline 2 & 10 & 110 & 35 & 4.33 & 352 & 129 & 0.89 & 66 & 40 & 0.421 & 19 & 2.51 & 23 \\
\hline 3 & 11 & 85 & 47 & 6.41 & 352 & 182 & 0.87 & 75 & 40 & 0.464 & 30 & 3.43 & 30 \\
\hline 4 & 11 & 38 & 53 & 6.81 & 426 & 230 & 0.87 & 92 & 40 & 0.362 & 14 & 4.34 & 13 \\
\hline 5 & 12 & 54 & 47 & 5.26 & 437 & 187 & 0.83 & 95 & 43 & 0.403 & 4 & 3.14 & 85 \\
\hline 6 & 13 & 35 & 66 & 6.92 & 350 & 227 & 0.87 & 85 & 46 & 0.462 & 14 & 3.73 & 33 \\
\hline 7 & 13 & 82 & 49 & 7.88 & 360 & 207 & 0.94 & 93 & 39 & 0.449 & 16 & 4.34 & \\
\hline 8 & 13 & 35 & 45 & 6.47 & 315 & 198 & 0.87 & 103 & 37 & 0.373 & 7 & 4.06 & 8 \\
\hline 9 & 13 & 45 & 49 & 6.61 & 382 & 190 & 0.98 & 86 & 40 & 0.377 & 25 & 4.12 & 47 \\
\hline 10 & 14 & 45 & 45 & 7.00 & 369 & 265 & 0.77 & 98 & 42 & 0.384 & 2 & 4.35 & 12 \\
\hline 11 & 14 & 60 & 32 & 5.15 & 207 & 146 & 0.93 & 98 & 39 & 0.410 & 11 & 3.04 & 9 \\
\hline 12 & 14 & 93 & 37 & 7.67 & 387 & 221 & 0.97 & 102 & 39 & 0.378 & 8 & 4.77 & 34 \\
\hline 13 & 14 & 50 & 51 & 6.29 & 411 & 206 & 0.80 & 100 & 35 & 0.352 & 8 & 4.08 & \\
\hline 14 & 14 & 65 & 55 & 7.29 & 552 & 231 & 0.85 & 105 & 38 & 0.301 & $\mathbf{0}$ & 4.51 & 22 \\
\hline 15 & 14 & 110 & 38 & 6.21 & 280 & 187 & 0.79 & 79 & 37 & 0.411 & 28 & 3.65 & 132 \\
\hline 16 & 14 & 88 & 32 & & & & - & 84 & 39 & & & & 48 \\
\hline 17 & 15 & 80 & 48 & 6.05 & 414 & 211 & 0.89 & 97 & 43 & 0.377 & 6 & 3.77 & 9 \\
\hline 18 & 15 & 52 & 36 & 5.38 & 261 & 157 & 0.86 & 90 & 39 & 0.438 & 16 & 3.02 & 59 \\
\hline 19 & 15 & 48 & 50 & 7.57 & 352 & 184 & 0.91 & 102 & 38 & 0.486 & 7 & 3.89 & 22 \\
\hline 20 & 15 & 55 & 51 & 5.31 & 322 & 104 & 0.93 & 91 & 30 & 0.477 & 25 & 2.78 & 55 \\
\hline 21 & 15 & 130 & 29 & 5.81 & 292 & 192 & 0.78 & 88 & 35 & 0.394 & 19 & 3.52 & 92 \\
\hline 22 & 16 & 70 & 52 & 6.86 & 333 & 280 & 0.82 & 63 & 41 & 0.450 & 13 & 3.77 & 32 \\
\hline 23 & 16 & 35 & 57 & 6.23 & 485 & 209 & 0.88 & 95 & 44 & 0.412 & 7 & 3.66 & 1 \\
\hline 24 & 16 & 100 & 37 & 6.74 & 222 & 144 & 0.93 & 76 & 41 & 0.576 & 33 & 2.86 & 149 \\
\hline 25 & 17 & 45 & 48 & 5.10 & 433 & 145 & 0.95 & 98 & 33 & 0.274 & 6 & 3.41 & \\
\hline 26 & 17 & 95 & 39 & 6.58 & 325 & 165 & 0.95 & 78 & 37 & 0.442 & 33 & 3.67 & 169 \\
\hline 27 & 18 & 56 & 52 & 5.95 & 345 & 147 & 0.94 & 91 & 39 & 0.444 & 17 & 3.31 & 19 \\
\hline 28 & 19 & 90 & 38 & 5.40 & 325 & 148 & 0.92 & 89 & 43 & 0.491 & 17 & 2.75 & 19 \\
\hline 29 & 19 & 90 & 61 & 8.56 & 399 & 279 & 0.86 & 97 & 45 & 0.537 & 0 & 3.96 & 129 \\
\hline 30 & 20 & 70 & 61 & 6.15 & 442 & 209 & 0.81 & 95 & 41 & 0.416 & 6 & 3.59 & 0 \\
\hline 31 & 20 & 130 & 42 & 5.49 & 268 & 193 & 0.84 & 73 & 46 & 0.441 & 24 & 3.07 & 89 \\
\hline 32 & 22 & 98 & 46 & 6.42 & 526 & 215 & 0.86 & 89 & 39 & 0.368 & 15 & 4.06 & 48 \\
\hline 33 & 23 & 98 & 44 & 8.46 & 601 & 225 & 0.88 & 87 & 34 & 0.404 & 23 & 5.04 & 60 \\
\hline 34 & 23 & 100 & 49 & 6.21 & 320 & 228 & 0.75 & 75 & 45 & 0.470 & 20 & 3.29 & 92 \\
\hline 35 & 23 & 90 & 61 & 7.67 & 355 & 225 & 0.81 & 91 & 40 & 0.435 & 12 & 4.00 & \\
\hline 36 & 25 & 90 & 45 & 6.26 & 344 & 176 & 0.80 & 83 & 38 & 0.482 & 20 & 3.24 & 79 \\
\hline 37 & 25 & 95 & 25 & 5.57 & 230 & 140 & 0.76 & 89 & 33 & 0.496 & 19 & 2.81 & 90 \\
\hline 38 & 26 & 68 & 57 & 5.98 & 871 & 238 & 0.79 & 94 & 39 & 0.289 & 6 & 4.25 & 79 \\
\hline 39 & 28 & 80 & 57 & 7.22 & 363 & 197 & 0.85 & 91 & 40 & 0.492 & 12 & 3.67 & 16 \\
\hline 40 & 29 & 85 & 41 & 6.55 & 339 & 169 & 0.87 & 91 & 40 & 0.517 & 14 & 3.16 & 69 \\
\hline 41 & 36 & 125 & 53 & 6.33 & 358 & 211 & 0.75 & 88 & 45 & 0.514 & 5 & 3.08 & 42 \\
\hline 42 & 42 & 150 & 39 & 3.81 & 246 & 173 & 0.76 & 79 & 56 & 0.467 & 1 & 2.03 & 21 \\
\hline 43 & 44 & 45 & 38 & 5.97 & 412 & 214 & 0.93 & 74 & 44 & 0.459 & 28 & 3.23 & 156 \\
\hline 44 & 52 & 92 & 36 & 4.00 & 219 & 157 & 0.72 & 73 & 53 & 0.538 & 9 & 1.85 & 47 \\
\hline 45 & 56 & 110 & 50 & 4.94 & 286 & 168 & 0.82 & 66 & 50 & 0.518 & 26 & 2.38 & 160 \\
\hline 46 & 57 & 75 & 58 & 7.70 & 295 & 221 & 0.93 & 53 & 78 & 0.431 & 15 & 4.38 & 289 \\
\hline 47 & 58 & 120 & 64 & 7.11 & 281 & 243 & 0.84 & 61 & 53 & 0.548 & 29 & 3.22 & 212 \\
\hline 48 & 61 & 110 & 43 & & & & - & 72 & 62 & & & & \\
\hline 49 & 65 & 40 & 55 & 6.63 & 289 & 195 & 0.85 & 78 & 52 & 0.593 & 13 & 2.78 & 78 \\
\hline 50 & 70 & 120 & 46 & 6.33 & 198 & 190 & 0.70 & & 48 & 0.365 & & 2.44 & 125 \\
\hline 51 & 72 & 40 & 54 & 10.61 & 455 & 278 & 0.91 & 77 & 49 & 0.576 & 19 & 4.50 & 59 \\
\hline Mean & 25.4 & 80.2 & 46.3 & 6.36 & 360 & 196 & 0.857 & 85.8 & 42.4 & 0.434 & 14.9 & 3.50 & 68.1 \\
\hline SD & 17.5 & 29.9 & 10.2 & 1.22 & 114 & 40 & 0.068 & 12.0 & 8.0 & 0.074 & 8.9 & 0.71 & 60.7 \\
\hline
\end{tabular}

the ventilation-blood flow maldistribution, these data were compared with normal data. With the data of Hart et al. (12), the anatomical dead space ( $V_{\text {Danat }}$ ) for each patient was predicted from the body weight, and Vnanat $V_{T}$ ratio estimated from the tidal volumes at which the $\mathrm{VD}_{\mathrm{D}} / \mathrm{V}_{\mathrm{T}}$ ratios were measured (Fig. 3). The figure il- lustrates a high incidence of $V_{n} / V_{T}$ ratios substantially greater than the predicted $\mathrm{V}_{\text {nanat }} / \mathrm{V}_{\text {r. }}$ The mean measured $V_{n} / V_{T}$ was $0.438 \pm 0.074(\mathrm{SD})$ and the mean predicted Vnanat/VT was $0.332 \pm 0.079$ (SD) (statistical significance of difference $(P<0.001)$. The AaDo's are compared with the data of Raine and Bishop (13) (Fig. 


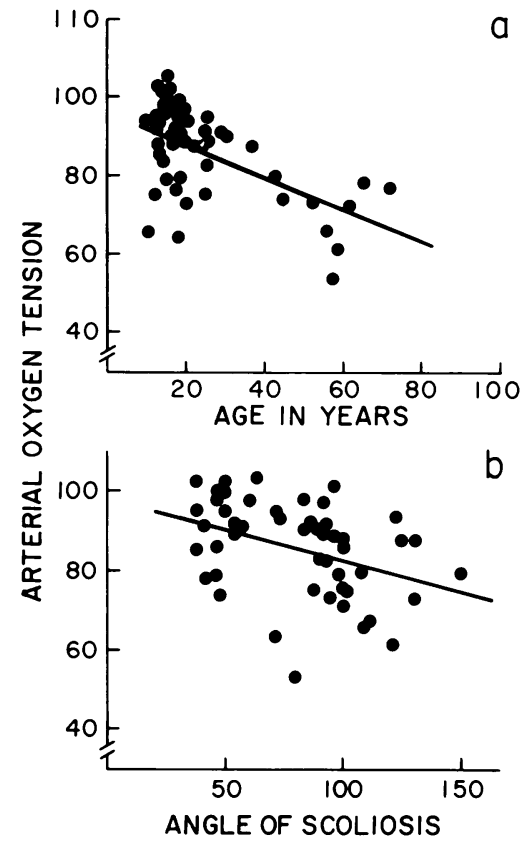

Figure 1 a. The relationship between age and the $\mathrm{PaO}_{2}$ while breathing air: the regression equation was $\mathrm{PaO}_{2}=$ $95.8-0.394 \mathrm{yr}, \mathrm{SE}$ slope \pm 0.094 , and $r=-0.574(P<0.001)$. $b$. The relationship between the angle and the $\mathrm{PaO}_{2}$ while breathing air: the regression equation was $\mathrm{PaO}_{2}=98.0-$ 0.152 angle, SE slope 0.062 , and $r=-0.377 \quad(P=0.01-$ $0.05)$.

4) : the data in the patients with scoliosis reveal a high level of AaDon, greater than that predicted by Raine and Bishop for the patient's age but in the patients with scoliosis there was no significant increase in this gradient with age. The $\mathrm{AaDo}_{2}$ was also inversely related to the VC (Fig. 5), percent predicted VC $(r=-0.339$, $P=0.01-0.05)$, and to the $\operatorname{Crs}(r=-0.463, P<$ 0.01 ).

The $\mathrm{V}_{\mathrm{n}} / \mathrm{V}_{\mathrm{r}}$ was directly related to the age, and the correlation coefficient for the total group was 0.473 $(P<0.01)$ (Fig. 6a). Although the correlation coefficients between angle and $V_{\mathrm{D}} / \mathrm{V}_{\mathrm{T}}$ were not significant, the correlation coefficients between $\mathrm{V}_{\mathrm{D}} / \mathrm{V}_{\mathrm{T}}$ and the $\mathrm{VC}$ (Fig. $6 b)$, and the $C_{r s}$ were significant $(r=-0.318, P=$ $0.01-0.05$ ).

The alveolar ventilation was inversely related to the age, and the angle of scoliosis (Fig. $7 a$ and $b$ ), and directly related to the VC $(r=0.544, P<0.001)$, percent predicted VC $(r=0.475, P<0.01)$ and $\mathrm{C}_{\mathrm{rs}}(r=0.453$, $P<0.01)$. These relationships were significant for the total group, as shown above, and both subgroups.

Oxygen consumption was directly related to the body weight $(r=0.581)$, and height $(r=0.593)$, and was also directly related to the $\mathrm{VC}$, percent predicted $\mathrm{VC}$, and $\mathrm{C}_{\mathrm{r}}$. The correlation coefficients between oxygen consumption and age and angle were not significant.
For each patient the oxygen consumption was normal for body size.

Relationships between age, angle, mechanical properties of the respiratory system, and the pattern of ventilation. These analyses were undertaken to test the hypothesis that the mechanical properties or age in scoliosis contribute to the pattern of ventilation, and by this mechanism contribute to the gas exchange abnormalities.

The minute ventilation was directly related to body weight, height, lung volumes, and the $\mathrm{C}_{\mathrm{rs}}$. For the patients $18 \mathrm{yr}$ or older, and for the patients with an angle of scoliosis $80^{\circ}$ or more, the minute ventilation was inversely related to the angle of scoliosis $(r=-0.423$ and -0.480 , respectively). The correlation coefficients between age and minute ventilation were not significant. The relationships between tidal vclume and body size, lung volumes, and the elastic properties of the respiratory system were similar to those of minute ventilation. For the total group, and for the patients with angle of scoliosis $80^{\circ}$ or more the tidal volume was inversely proportional to the angle $(r=-0.312$ and $r=-0.389$, respectively). Therefore, in severe scoliosis there is a consistent inverse relationship between the angle and
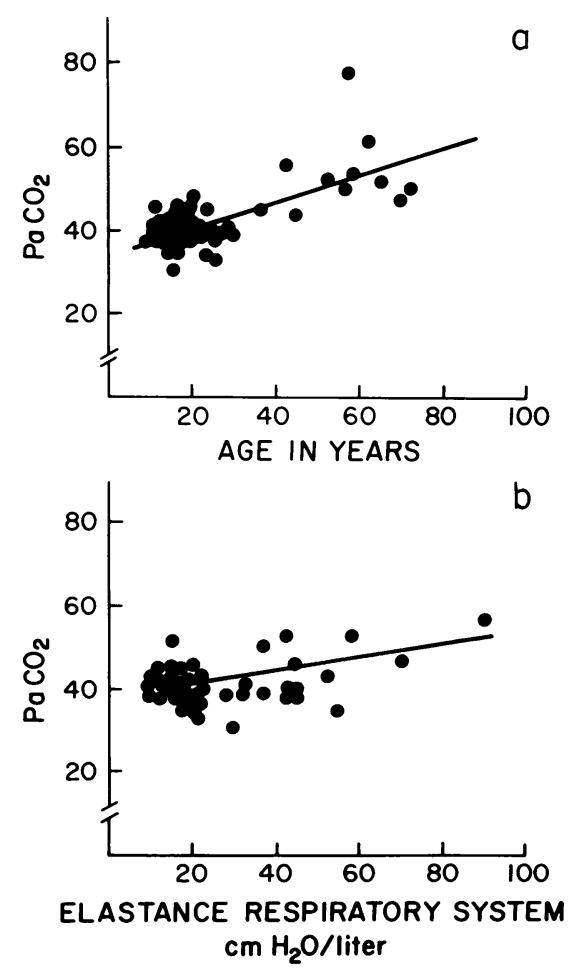

Figure $2 a$. The relationship between age and the $\mathrm{PaCO}_{2}$ while breathing air: the regression equation was $\mathrm{PaCO}_{2}=$ $34.2+0.323 \mathrm{yr}, \mathrm{SE}$ slope \pm 0.052 and $r=0.710(P<0.001)$. $b$. The relationship between elastance of the respiratory system and the $\mathrm{PaCO}_{2}=37.7+0.166$ elastance, $\mathrm{SE}$ slope 0.068 , and $r=0.379(P=0.001-0.01)$. 


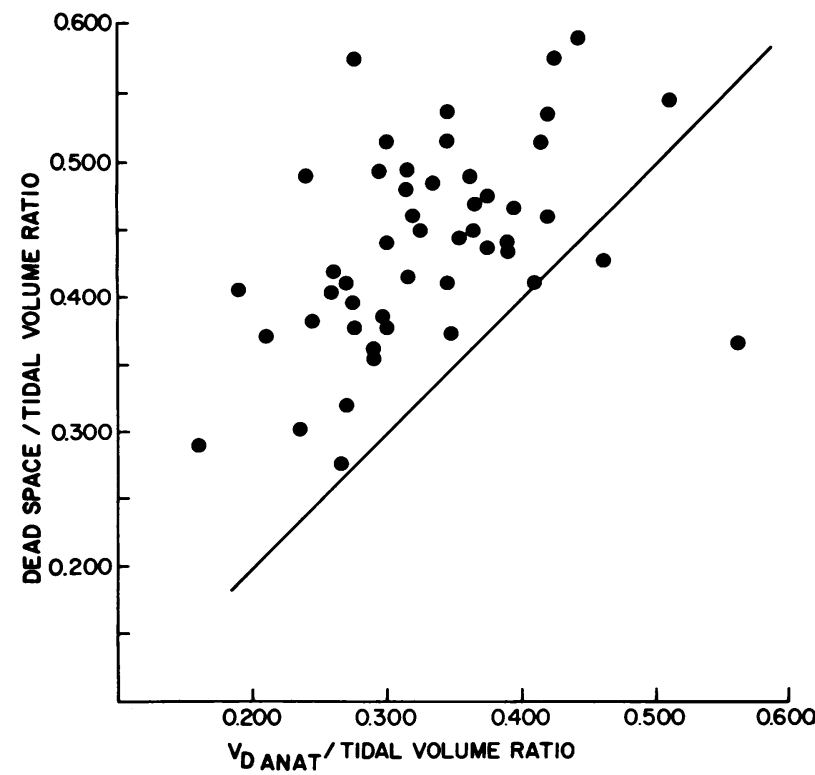

FIGURE 3 The relationship between the measured $V_{D} / V_{T}$ $\left(V_{\text {D physologieal }} / V_{T}\right)$ and the predicted $V_{\text {Danat }} / V_{T}$. The $V_{\text {Danat }}$ was predicted from the body weight of each patient from the regression equation $V_{\text {Danat }}=1.835$ weight (in kilograms) $+26.6 ; r=0.829$ (12). The $\mathrm{V}_{\mathrm{T}}$ was the tidal volume under the conditions of measurement of $V_{D} / V_{T}$. Continuous line is the line of identity.

both the minute ventilation and the tidal volume. The correlation coefficient between age and tidal volume was also statistically significant for patients with angle of scoliosis $80^{\circ}$ or more $(r=-0.374)$. The correlation coefficients between respiratory frequency and age, angle, and mechanical properties of the respiratory system were also significant. For the total group, and both subgroups, there was a direct relationship between age and the respiratory frequency: total group, $r=$ 0.411 ; angle $80^{\circ}$ or more, $r=0.419$, and patients $18 \mathrm{yr}$ or over $r=0.580$. For all patients the respiratory frequency was also inversely proportional to the VC $(r=$ $-0.393)$, percent predicted VC $(r=-0.449)$, and the Crs $(r=-0.463)$; however, these relationships were not consistently significant for the two subgroups.

Relationships between the pattern of ventilation and the arterial blood gases and gas exchange variables. Statistically significant relationships were also demonstrable between the pattern of ventilation and the arterial blood gases and indices of ventilation/blood flow. The correlation coefficients between tidal volume and the following variables for the total group were: $\mathrm{PaO}_{2}, r=$ $0.343(P=0.001-0.01) ; \mathrm{Pac0}_{2}, r=-0.232(P>0.05)$; $\mathrm{V}_{\mathrm{D}} / \mathrm{V} \mathrm{x}, r=-0.458 \quad(P<0.001) ; \mathrm{AaDoz}, r=-0.303$ $(P=0.01-0.05)$, and alveolar ventilation, $r=0.606(P<$ $0.01)$. In general the relationships between tidal volume and the gas exchange variables were similar for each of the subgroups. The correlation coefficients between

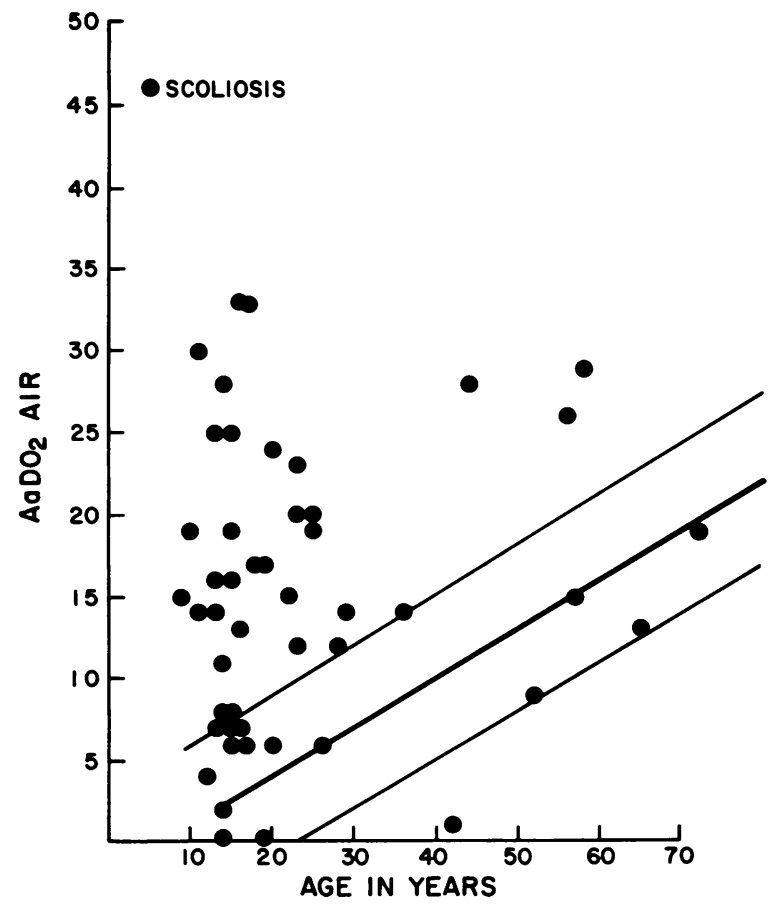

FIgUre 4 The relationship between the measured AaDon (air) and the $\mathrm{AaDo}_{2}$ (air) predicted from age on the basis of the regression equation of Raine and Bishop (13) : AaDo, (air) $=0.36 \mathrm{yr}-4.3, \mathrm{SD}$ of estimate $\pm 5.6 \mathrm{~mm} \mathrm{Hg}$.

respiratory frequency, and the following variables for the total group were : $\mathrm{PaO}_{2}, r=-0.365(P=0.001-$ $0.01) ; \mathrm{PaCO}_{2}, r=0.326(P=0.01-0.05) ; \mathrm{V}_{\mathbf{D}} / \mathrm{V}_{\mathbf{T}}, r=$ $0.519(P<0.001)$; AaDo2, $r-0.381(P=0.001-0.01)$, and alveolar ventilation, $r=-0.175(P<0.05)$. Although these relationships were similar for the patients

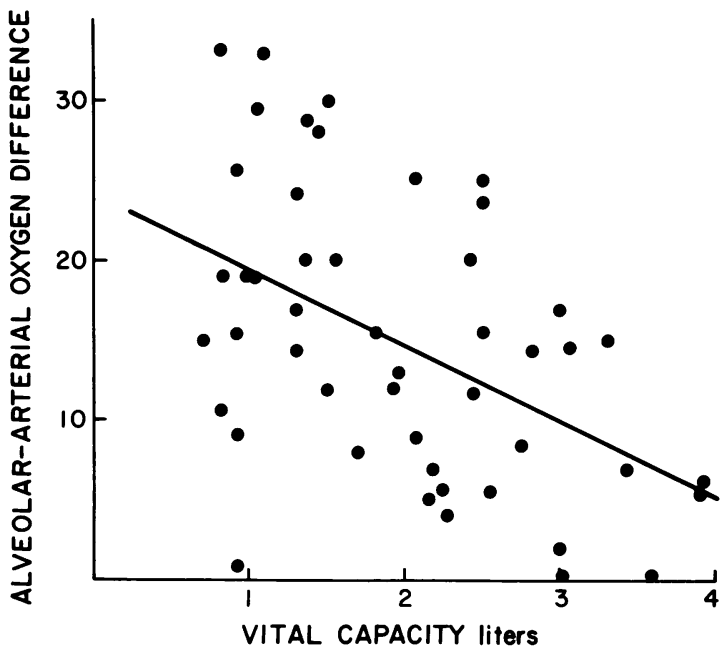

Figure 5 The relationship between the $\mathrm{VC}$ and the $\mathrm{AaDo}_{2}$ breathing air: the regression equation was $\mathrm{AaDo}_{2}=24.2-$ 4.78 vital capacity, SE slope 1.429 , and $r=-0.487(P<$ 0.001 ). 

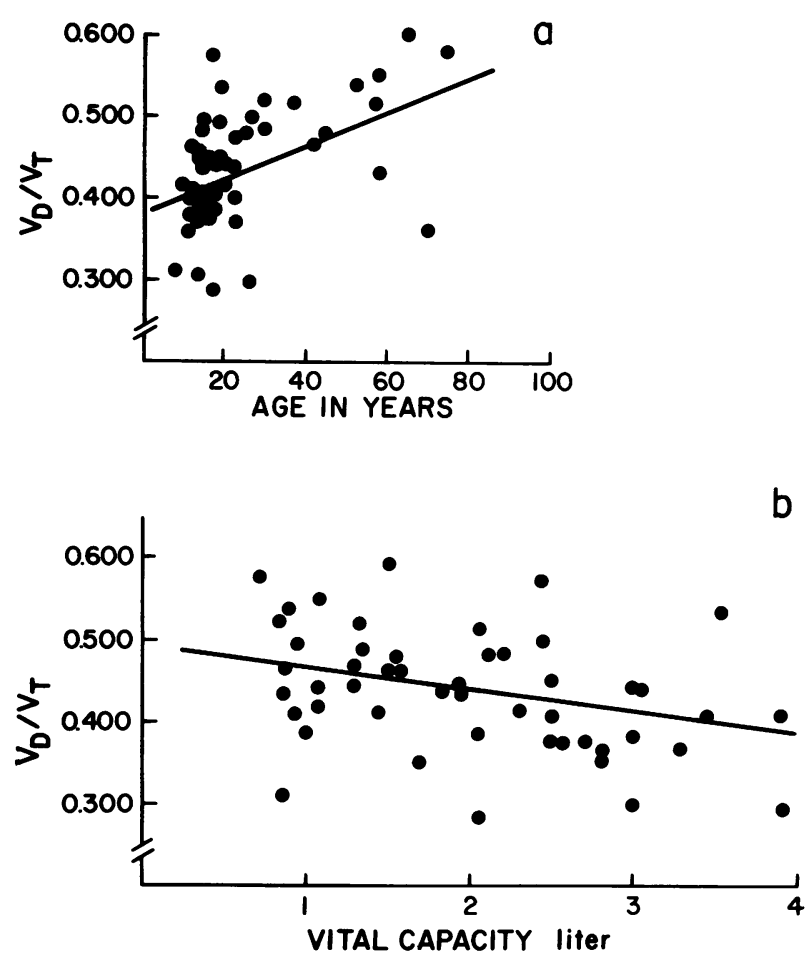

Figure 6 a. The relationship between the age and the $\mathrm{V}_{\mathrm{D}} / \mathrm{V}_{\mathrm{T}}$ while breathing air: the regression equation was $\mathrm{V}_{\mathrm{D}} / \mathrm{V}_{\mathrm{T}}=0.387+0.002 \mathrm{yr}, \mathrm{SE}$ slope \pm 0.0006 and $r=0.473$ $(P<0.001)$. b. The relationship between the vital capacity and the $\mathrm{V}_{\mathrm{D}} / \mathrm{V}_{\mathrm{T}}$ : regression $=0.495-0.029 \mathrm{VC}, \mathrm{SE}$ slope 0.013 , and $r=-0.361(P<0.001)$.

$18 \mathrm{yr}$ or over, only the correlation coefficient between respiratory frequency and $\mathrm{AaDos}$ was significant for patients with angle $80^{\circ}$ or more.

$\mathrm{PaO}$, and $\mathrm{AaDO}$, breathing $100 \%$ oxygen. The mean Paoa breathing $100 \%$ oxygen was $607 \pm 70$ (SD) $\mathrm{mm}$ $\mathrm{Hg}$, and the mean $\mathrm{AaDo}_{2}$ was $64 \pm 61$ (SD) $\mathrm{mm} \mathrm{Hg}$. The AaDos (oxygen) was directly related to age, $r=$ $-0.480(P<0.01)$, and the regression equation was $\mathrm{AaDo}_{2}$ (oxygen) $=25.6+1.676$ yr.

\section{DISCUSSION}

Age-dependent changes in arterial blood gases. In normal man throughout life there is an age-dependent decrease in the $\mathrm{PaO}_{2}$; and although the populations and the criteria for normality varied between studies, the relationships between the age and the $\mathrm{PaO}_{2}$ were consistent (13-17). However, in the patients with scoliosis both the intercept on the ordinate was lower, and the rate of decrease of $\mathrm{PaO}_{2}$ with age $\left(\Delta \mathrm{PaO}_{2} / \Delta \mathrm{yr}\right)$ was greater than in the normal subjects, except for the rate of decrement with age the study of Sorbini et al. (17). The reason for the differences between Sorbini and associates' study and the others is unknown. Although it might be reasoned that an industrial urban population (13), smokers, and supine subjects $(13,14,17)$ would show a greater rate of decrease in $\mathrm{PaO}$ with age, this was not evidenced by comparisons between or within these series. In contrast to normal man, in whom there is no variation in $\mathrm{PaCO}$ with age $(13,14,16-18)$, in scoliosis the $\mathrm{PaCO}_{2}$ increased with age. Therefore, throughout the evolution of the respiratory function abnormalities in scoliosis, there is a progressive decrease in $\mathrm{PaO}_{2}$, and an increase in $\mathrm{PacO}_{2}$. Since the $\mathrm{AaDo}$ breathing air does not increase with age, the decrement in $\mathrm{PaO}_{2}$ with age seems best explained by the progressive fall in alveolar ventilation and consequent hypercapnia.

Ventilation-blood flow maldistribution and impaired ventilatory compensation. Three major mechanisms contribute to blood gas abnormalities while breathing air: hypoventilation, ventilation-blood flow maldistribution, and impairment to diffusion (19). In examining the mechanism of blood gas abnormalities in scoliosis, a distinction must be made between alveolar hypoventilation due to reduction in ventilation and that due to ventilation-blood flow maldistribution. Ventilation-blood flow maldistribution not only impairs the exchange of oxygen but also of carbon dioxide, and hypercapnia occurs in the absence of a compensatory increase in ventilation $(20,21)$. It also follows that normocapnia in the
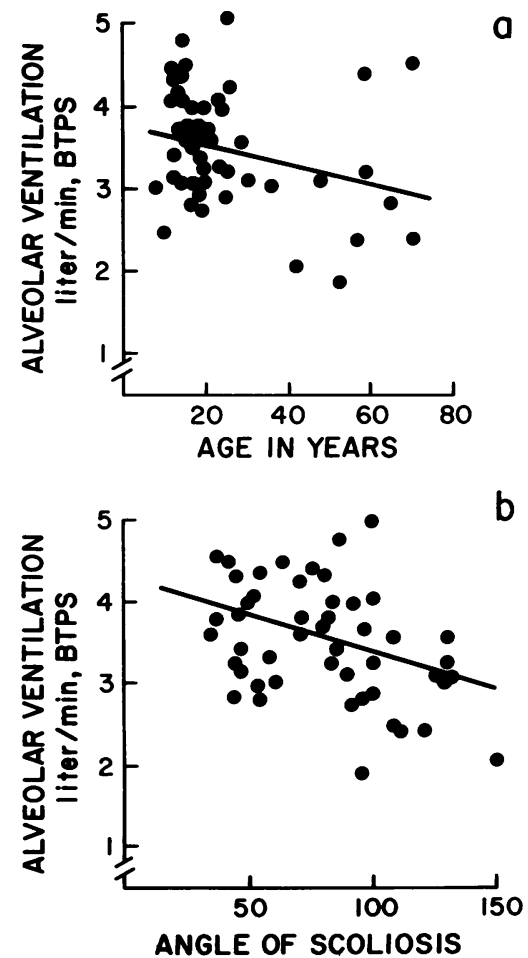

Figure 7 a. The relationship between the age and alveolar ventilation: regression equation was $\hat{\nabla}_{\Delta}=3.797-0.012 \mathrm{yr}$, SE slope 0.0065 , and $r=-0.289(P=0.01-0.05)$. $b$. The relationship between the angle and the alveolar ventilation: regression equation was $\mathrm{V}_{\Delta}=4.248-0.009$ angle, $\mathrm{SE}$ slope 0.004 , and $r=-0.391(P=0.001-0.01)$. 
presence of ventilation-blood flow maldistribution is evidence of a compensatory increase in ventilation.

In scoliosis, as evidenced by the elevated $V_{D} / V_{T}$ ratios and $\mathrm{AaDoz}$, ventilation-blood flow maldistribution is a mechanism of the blood gas abnormalities. Furthermore, the association of normocapnia and ventilationblood flow maldistribution in the early decades of evolution of the functional changes confirms the presence of a compensatory increase in ventilation. Hence it is argued that the primary mechanism of blood gas abnormalities in scoliosis is ventilation-blood flow maldistribution. However, with increasing age several processes occur. First, as in normal man, the $\mathrm{V}_{\mathrm{n}} / \mathrm{V}_{\mathrm{T}}$ increases, but in contrast to the normal data, in scoliosis both the intercept and the rate of increase per year are greater $(13,16)$. The rate of increase in $V_{D} / V_{T}$ ratio per year in the sitting position in Raine and Bishop's study was 0.001 , and this slope is not significantly different from zero (SD of estimate 0.062) (13). The rate of increase per year in Mellemgaard's study (16) did approach that of the patients with scoliosis and was $0.0017 / \mathrm{yr}$. Second, the alveolar ventilation decreases and the $\mathrm{PaCO}_{2}$ increases with age. The simplest explanation of these events is a progressive deterioration of ventilation-blood flow maldistribution, as evidenced by the increasing $\mathrm{V}_{\mathrm{n}} / \mathrm{V}_{\mathrm{r}}$, and failure of a compensatory increase in ventilation to maintain normocapnia.

The data presented in an earlier paper on the mechanical properties of the respiratory system and the ventilatory response to $\mathrm{CO}_{2}$ show that several factors may contribute to an impaired chemical regulation of ventilation and hence, by inference, impair compensation for ventilation-blood flow maldistribution (11). The slope of both the tidal volume and the minute ventilation response to $\mathrm{CO}_{2}$ were directly proportional to the $\mathrm{VC}$,

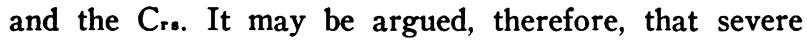
deformity prevents the compensatory increase in ventilation by mechanically impeding ventilation. Several agerelated changes may also contribute to the failure of a compensatory increase in ventilation. First, as has been shown in normals, there is an age-dependent decrease in the slope of the ventilatory response to $\mathrm{CO}_{2}(11,22)$. Second, the compensatory increase in ventilation may have been overwhelmed by the magnitude of increase in $V_{\mathbf{D}} / \mathrm{V}_{\mathbf{T}}$.

In several of the older patients, the $\mathrm{AaDo}_{2}$ breathing oxygen was greater than $200 \mathrm{~mm} \mathrm{Hg}$, and in these patients pulmonary arteriovenous shunt may have contributed to the $\mathrm{AaDo}$ while breathing air. However this interpretation is questionable on the basis of the studies by Wagner and associates $(23,24)$ who, using multiple inert gas elimination techniques to measure continuous $\dot{V}_{\triangle} / \dot{Q}$ distribution, demonstrated the development of shunt in awake subjects spontaneously breathing $100 \%$ oxy- gen. These changes were most frequent in the older subjects. In a theoretical paper (24), they provided evidence that the shunt on $100 \% \mathrm{O}_{2}$ would develop in lung units with critically low ventilation-perfusion ratios. The possibilities are, therefore: with increasing age, the contribution of pulmonary arteriovenous shunt to the $\mathrm{AaDos}_{3}$ breathing air increases; and/or areas with critically low $\dot{\mathrm{V}}_{\mathrm{A}} / \dot{Q}$ ratios increase with age and are evidenced as large $\mathrm{AaDo}_{2}$ while breathing oxygen.

Mechanism of elevated $V_{D} / V_{T}$ and ventilation-blood flow maldistribution. The conventional concept of the mechanism of elevated $V_{D} / V_{T}$ ratios and the ensuing alveolar hypoventilation in scoliosis was that these were due to the abnormal ventilatory pattern of small tidal volumes with a high respiratory frequency (3-5). The respiratory frequency was directly related and the tidal volume inversely related to the $V_{D} / V_{T}$, which would support the conventional concept; however, these associations do not necessarily provide evidence of causeand-effect relationships. Physiological dead space consistently exceeded the predicted anatomical dead space; suggesting a significant component of mismatching between blood flow and ventilation in patients with scoliosis. Therefore it may be argued that the physiological dead space/tidal volume ratio is elevated as a result of ventilation/blood flow maldistribution due to the deformity of the rib cage, and that the pattern of ventilation (abnormally high respiratory frequency and small tidal volumes) may further contribute to the elevated $\mathrm{V}_{\mathrm{D}} / \mathrm{V}_{\mathrm{T}}$ ratios.

It may be postulated that the ventilation-blood flow maldistribution is the result of several mechanisms. First, histologic studies of the lungs in scoliosis have shown a nonuniform distribution of alveolar volume with areas of compression, and a nonuniform distribution of vessels with areas of decreased vascularity (25-26). Second, in scoliosis the relative contribution of the diaphragm to the tidal volume is greater than normal (27), and this decreased contribution of the rib cage to inflation may contribute to an abnormal distribution of ventilation. Regional studies on the distribution of ventilation and blood flow have shown an abnormal distribution of ventilation and blood flow in scoliosis; however, there are no data on quantitative relationships between these abnormalities and indices of ventilation-blood flow maldistribution of blood gases (28-31). Although our study has demonstrated statistically significant quantitative relationships between the indices of ventilationblood flow maldistribution and the lung volumes and the mechanical properties of the respiratory system, other techniques are required to demonstrate the mechanism of ventilation-blood flow maldistribution in scoliosis.

Pattern of ventilation. The data have shown that the respiratory frequency is inversely related to the $\mathrm{C}_{\mathrm{r} s}$ and 
the $\mathrm{VC}$, and the tidal volume is directly related to the $\mathrm{C}_{\mathrm{r}}$. and the VC. These associations are consistent with the hypotheses of optimal respiratory frequency to minimize inspiratory work or force $(32,33)$; however, the absence of data on the total resistance of the respiratory system and the limitations of the sine wave model of breathing precluded a rigorous examination of these hypotheses.

In conclusion, this study has demonstrated that in scoliosis two primary variables, age and the degree of chest wall deformity, contribute to the abnormalities in gas exchange and arterial blood gases. Ventilation-blood flow maldistribution, directly related to the deformity of the rib cage. is the major source of impaired gas exchange in young patients with scoliosis; aging causes further deterioration in ventilation-blood flow maldistribution, and finally failure of the expected response to a rising physiological dead space ultimately leads to hypercapnia. Age-dependent changes in the pattern of the ventilation (i.e. a rising frequency and falling tidal volume) and the age-dependent decreases in the slope of the ventilatory response to $\mathrm{CO}_{2}$ both may contribute to the ultimate $\mathrm{CO}$ z retention. This is the first demonstration in scoliosis of statistically significant relationships between the deformity. as expressed by the angle or as lung volumes. the elastic properties of the respiratory system. age. and the arterial blood gases and gas exchange variables.

\section{ACKNOWLEDGMENTS}

I am grateful to Mr. Peter Donnelly for the excellence of his technical assistance, and to Maria Gregoris for her secretarial assistance.

This investigation was supported by the Life Insurance Medical Research Fund of Australia and New Zealand, North Carolina Lung Association, and grant HL-17314-01 from the Heart and Lung Institute of the National Institutes of Health.

\section{REFERENCES}

1. Chapman, E. M., D. B. Dill, and A. Graybiel. 1939. The decrease in the functional capacity of the lungs and heart resulting from deformities of the chest: Pulmonocardiac failure. Medicine (Baltimore). 18: 167-202.

2. Hanley, T., M. M. Platts, M. Clifton, and T. L. Morris. 1958. Heart failure of the hunchback. Q. J. Med. 27 : 155-171.

3. Bergofsky, E. H., G. M. Turino, and A. P. Fishman. 1959. Cardiorespiratory failure in kyphoscoliosis. Medicine (Baltimore). 38: 263-317.

4. Turino, G. M., R. M. Goldring, and A. P. Fishman. 1965. Cor pulmonale in musculoskeletal abnormalities of the thorax. Bull. N. Y. Acad. Med. 41: 959-980.

5. Fishman, A. P., R. M. Goldring, and G. M. Turino. 1966. General alveolar hypoventilation: A syndrome of respiratory and cardiac failure in patients with normal lungs. Q. J. Med. 35 : 261-275.

6. Shaw, D. B., and J. Read. 1960. Hypoxia and thoracic scoliosis. Br. Med. J. 2 : 1486-1489.
7. Bruderman, I., and M. Stein. 1961. Physiologic evalua. tion and treatment of kyphoscoliotic patients. Ann. Intern. Med. 55: 94-102.

8. Freyschuss, U., U. Nilsonne, and K.-D. Lundgren. 1968. Idiopathic scoliosis in old age. I. Respiratory function. Acta Med. Scand. $184: 365-372$.

9. Makley, J. T., C. H. Herndon, S. Inkley, C. Doershuk, L. W. Matthews, R. H. Post, and A. S. Littell. 1968. Pulmonary function in scoliosis and non-paralytic scoliosis before and after treatment. A study of sixty-three cases. J. Bone Jt. Surg. Am. Vol. 50: 1379-1390.

10. Weber, B., J. P. Smith, W. A. Briscoe, S. A. Friedman, and T. K. C. King. 1975. Pulmonary function in asymptomatic adolescents with idiopathic scoliosis. Am. Rer. Respir. Dis. 111 : 389-397.

11. Kafer, E. R. 1975. Idiopathic scoliosis. Mechanical properties of the respiratory system and the ventilatory response to carbon dioxide. J. Clin. Invest. 55: 11531163.

12. Hart, M. C., M. M. Orzalesi, and C. D. Cook. 1963. Relation between anatomic respiratory dead space and body size and lung volume. J. Appl. Physiol. 18: 519522 .

13. Raine, J. M., and J. M. Bishop. 1963. A-a difference in $\mathrm{O}_{2}$ tension and physiological dead space in normal man. J. Appl. Physiol. 18: 284-288.

14. Marshall, B. E., and R. A. Millar. 1965. Some factors influencing post-operative hypoxaemia. Anaesthesia. 20: 408-428.

15. Conway, C. M., J. P. Payne, and P. J. Tomlin. 1965. Arterial oxygen tension of patients awaiting surgery. Br. J. Anaesth. $37:$ 405-408.

16. Mellemgaard, K. 1966. The alveolar-arterial oxygen difference: Its size and components in normal man. Acta Phy'siol. Scand. 67: 10-20.

17. Sorbini, C. A., V. Grassi, E. Solinas, and G. Muiesan. 1968. Arterial oxygen tension in relation to age in healthy subjects. Respiration. 25: 3-13.

18. Siggaard-Andersen, O. 1965. The Acid-Base Status of the Blood. Munksgaard, A/S, Copenhagen, Denmark. 28.

19. Farhi, L. E., and H. Rahn. 1955. A theoretical analysis of the alveolar-arterial $\mathrm{O}_{2}$ difference with special reference to the distribution effect. J. Appl. Physiol. 7 : 699-703.

20. West, J. B. 1969. Ventilation-perfusion inequality and overall gas exchange in computer models of the lung. Respir. Physiol. 7 : 88-110.

21. West, J. B. 1971. Causes of carbon dioxide retention in lung disease. N. Engl. J. Mcd. 284: 1232-1236.

22. Kronenberg, R. S., and C. W. Drage. 1973. Attentuation of the ventilatory and heart rate responses to hypoxia and hypercapnia with aging in normal men. $J$. Clin. Inc'cst. 52: 1812-1819.

23. Wagner, P. D., R. B. Laravuso, R. R. Uhl, and J. B. West. 1974. Continuous distributions of ventilation-perfusion ratios in normal subjects breathing air and $100 \%$ $\mathrm{O}_{2 .}$ J. Clin. Invest. $54: 54-68$.

24. Dantzker, D. R., P. D. Wagner, and J. B. West. 1975. Instability of lung units with low $\dot{\mathrm{V}} \mathrm{A} / \dot{\mathrm{Q}}$ ratios during $\mathrm{O}_{2}$ breathing. J. Appl. Phy'siol. 38: 886-895.

25. Reid, L. 1966. Autopsy studies of the lungs in kyphoscoliosis. In Proceedings of a Symposium on Scoliosis. P. A. Zorab, editor. National Fund for Research into Poliomyelitis and Other Crippling Diseases, London. 71-78. 
26. Davies, G., and L. Reid. 1971. Effect of scoliosis on growth of alveoli and pulmonary arteries and on right ventricle. Arch. Dis. Child. 46: 623-632.

27. Jordanoglu, J. 1969. Rib movement in health, kyphoscoliosis, and ankylosing spondylitis. Thorax. 24: 407-414.

28. Westgate, H. D. 1967. Pulmonary function in scoliosis. Am. Rev. Respir. Dis. 96: 147.

29. Dollery, C. T., P. M. S. Gillam, P. Hugh-Jones, and P. A. Zorab. 1965. Regional lung function in kyphoscoliosis. Thorax. 20 : 175-181.

30. Shannon, D. C., E. J. Riseborough, L. M. Valenca, and H. Kazemi. 1970. The distribution of abnormal lung function in kyphoscoliosis. J. Bone Jt. Surg. Am. Vol. 52 : 131-144.

31. Bake, B., J. Bjure, J. Kasalichý, and A. Nachemson. 1972. Regional pulmonary ventilation and perfusion distribution in patients with untreated idiopathic scoliosis. Thorax. 27 : 703-712.

32. Mead, J. 1960. Control of respiratory frequency. $J$. Appl. Physiol. 15: 325-336.

33. Otis, A. B., W. O. Fenn, and H. Rahn. 1950. Mechanics of breathing in man. J. Appl. Physiol. 2: 592-607. 